\title{
Video Article \\ Fluorescence-based Neuraminidase Inhibition Assay to Assess the Susceptibility of Influenza Viruses to The Neuraminidase Inhibitor Class of Antivirals
}

\author{
Sook-Kwan Leang ${ }^{1}$, Aeron C. Hurt ${ }^{1}$ \\ ${ }^{1}$ WHO Collaborating Centre for Reference and Research on Influenza, Peter Doherty Institute for Infection and Immunity \\ Correspondence to: Aeron C. Hurt at aeron.hurt@influenzacentre.org
}

URL: https://www.jove.com/video/55570

DOI: doi: $10.3791 / 55570$

Keywords: Immunology, Issue 122, Fluorescence, neuraminidase, resistance, influenza, MUNANA, antiviral, inhibitor, phenotypic assay, oseltamivir, zanamivir

Date Published: 4/15/2017

Citation: Leang, S.K., Hurt, A.C. Fluorescence-based Neuraminidase Inhibition Assay to Assess the Susceptibility of Influenza Viruses to The Neuraminidase Inhibitor Class of Antivirals. J. Vis. Exp. (122), e55570, doi:10.3791/55570 (2017).

\section{Abstract}

The neuraminidase (NA) inhibitors are the only class of antivirals approved for the treatment and prophylaxis of influenza that are effective against currently circulating strains. In addition to their use in treating seasonal influenza, the NA inhibitors have been stockpiled by a number of countries for use in the event of a pandemic. It is therefore important to monitor the susceptibility of circulating influenza viruses to this class of antivirals. There are different types of assays that can be used to assess the susceptibility of influenza viruses to the NA inhibitors, but the enzyme inhibition assays using either a fluorescent substrate or a chemiluminescent substrate are the most widely used and recommended. This protocol describes the use of a fluorescence-based assay to assess influenza virus susceptibility to NA inhibitors. The assay is based on the NA enzyme cleaving the 2'-(4-Methylumbelliferyl)-a-D-N-acetylneuraminic acid (MUNANA) substrate to release the fluorescent product 4methylumbelliferone (4-MU). Therefore, the inhibitory effect of an NA inhibitor on the influenza virus NA is determined based on the concentration of the NA inhibitor that is required to reduce $50 \%$ of the NA activity, given as an $\mathrm{IC}_{50}$ value.

\section{Video Link}

The video component of this article can be found at https://www.jove.com/video/55570/

\section{Introduction}

Haemagglutinin (HA) and neuraminidase (NA) are the two major surface glycoproteins of influenza $A$ and $B$ viruses. $H A$ binds to the sialic acid-galactose of cell surface glycoproteins or glycolipids, while the NA releases virus by cleaving the sialic acid from the galactose on the cell surface ${ }^{1}$. The NA inhibitors are a class of influenza antivirals that were rationally designed to bind tightly to the NA enzymatic active site, thereby preventing the release and spread of virus progeny. Oseltamivir and zanamivir are two NA inhibitors that have been approved in many countries worldwide for the treatment and prophylaxis of influenza. In recent years, two additional NA inhibitors, peramivir and laninamivir, have been approved for use in a limited number of countries. Screening of influenza viruses for susceptibility to NA inhibitors and the identification of mutations that confer resistance are important in determining and monitoring the effectiveness of this class of antivirals.

In the last 16 years, the fluorescence-based NA inhibition assay has been performed routinely at the WHO Collaborating Centre for Reference and Research on Influenza, Melbourne (Melbourne WHOCCRRI) to monitor the changing trend of antiviral susceptibility among circulating influenza viruses. Annually, more than 2,000 influenza viruses are tested for antiviral susceptibility. In most influenza seasons, $>98 \%$ of the viruses are susceptible to all four NA inhibitors ${ }^{2,3,4}$, although during the 2007-2008 northern hemisphere influenza season, there was a surge in the number of former seasonal $\mathrm{A}(\mathrm{H} 1 \mathrm{~N} 1)$ viruses that had reduced susceptibility to oseltamivir ${ }^{5}$. This group of viruses, which contained the NA amino acid substitution $\mathrm{H} 275 \mathrm{Y}$, spread to the rest of the world by the end of 2008 , making oseltamivir inappropriate globally for the treatment of this virus. The vast majority of currently circulating influenza $B$, influenza $A(H 3 N 2)$, and influenza $A(H 1 N 1)$ pdm09 strains are susceptible to oseltamivir, although community clusters of $\mathrm{A}(\mathrm{H} 1 \mathrm{~N} 1)$ pdm09 variants containing the $\mathrm{NA}$ amino acid substitution $\mathrm{H} 275 \mathrm{Y}$ that confers reduced oseltamivir and peramivir susceptibility, have been reported in various parts of the world ${ }^{6,7}$.

Because of the need for a sufficiently high virus titer, clinical specimens (including animal nasal washes) must be passaged in either cell culture or embryonated chicken eggs prior to antiviral susceptibility testing. The NA inhibition assay described in this article can be divided into three sections:

Determining the linear range for the fluorescent product 4-methylumbelliferone (4-MU) on a particular fluorometer

Due to the inherent differences between fluorometers, the linear range for the fluorescent end-product, 4-MU, and the relative fluorescence unit (RFU), need to be established. Once the linear range for 4-MU is established, the optimal target signal is selected, to which the concentration of the influenza viruses is adjusted in the NA activity assay. Once completed for a particular fluorometer, this should not need to be repeated.

Determining the NA activity of the viruses 
The NA activity assay is a simple assay that involves the addition of the 2'-(4-Methylumbelliferyl)-a-D-N-acetylneuraminic acid (MUNANA) substrate to serially diluted viruses. The amount of fluorescent end-product 4-MU generated from the cleavage of MUNANA by the NA is measured using a fluorometer. The appropriate virus dilution to use in the NA inhibition assay is selected by plotting fluorescence units against virus dilution. From the sigmoidal curve produced, the mid-point of the linear section should correspond to the 4-MU linear range of the fluorometer determined in section 1 and will inform the appropriate concentration of viruses to be used in section 3 .

Assessing virus susceptibility to NA inhibitors using the NA inhibition assay

To assess the susceptibility of viruses to a particular NA inhibitor, viruses at the dilution determined in section 2 are incubated with a range of NA inhibitor concentrations. Following a subsequent incubation with MUNANA, the 4-MU generated by uninhibited viruses is measured in RFU by the fluorometer. The inhibitory effect of the NA inhibitor on the NA enzyme activity of a virus is calculated according to the NA inhibitor concentration required to reduce $50 \%$ of the NA activity, given as an $\mathrm{IC}_{50}$ value.

\section{Determining the Linear Range of Fluorescent Product 4-MU on a Fluorometer}

1. Prepare $10 \mathrm{~mL}$ of $6.4 \mathrm{mM}$ 4-MU stock solution by dissolving $11.3 \mathrm{mg}$ of $4-\mathrm{MU}$ in $5 \mathrm{~mL}$ of absolute ethanol. Add $5 \mathrm{~mL}$ of $0.9 \% \mathrm{NaCl}$ (w/v) to the stock solution to make $10 \mathrm{~mL}$. Prepare a $640 \mu \mathrm{M}$ working solution by diluting $1 \mathrm{~mL}$ of $6.4 \mathrm{mM} 4-\mathrm{MU}$ in $9 \mathrm{~mL}$ of $1 \mathrm{x}$ assay buffer (33.3 mM 2-(N-morpholino)ethanesulfonic acid (MES) and $4 \mathrm{mM} \mathrm{CaCl}_{2}, \mathrm{pH} 6.5$ ).

NOTE: Prepare the $2 \mathrm{x}$ assay buffer by adding $13 \mathrm{~g}$ of MES and $8 \mathrm{~mL}$ of $1 \mathrm{M} \mathrm{CaCl}_{2}$ to $992 \mathrm{~mL}$ of distilled water. Adjust the pH to $6.5 \mathrm{using} 10$ $\mathrm{M}$ of $\mathrm{NaOH}$. Filter the buffer using a sterile cellulose acetate filter of pore size $0.2 \mu \mathrm{m}$. Caution! Sodium hydroxide is caustic and may cause chemical burns to the skin and eyes. Ensure that full personal protective equipment is worn.

2. Prepare $5 \mathrm{~mL}$ of a range of $4-\mathrm{MU}$ concentrations (i.e., $5 \mu \mathrm{M}, 10 \mu \mathrm{M}, 20 \mu \mathrm{M}, 40 \mu \mathrm{M}, 80 \mu \mathrm{M}, 160 \mu \mathrm{M}$, and $320 \mu \mathrm{M}$ ) through a two-fold serial dilution of $640 \mu \mathrm{M} 4-\mathrm{MU}$ using $1 \mathrm{x}$ assay buffer.

3. Dispense $50 \mu \mathrm{L}$ of each serial dilution of $4-\mathrm{MU}$ (i.e., $5 \mu \mathrm{M}, 10 \mu \mathrm{M}, 20 \mu \mathrm{M}, 40 \mu \mathrm{M}, 80 \mu \mathrm{M}, 160 \mu \mathrm{M}, 320 \mu \mathrm{M}$ and $640 \mu \mathrm{M}$ ) (two wells per dilution) into a clear, 96 -well flat-bottom plate and $50 \mu \mathrm{L}$ of $1 \mathrm{x}$ assay buffer into the remaining wells (which serve as blanks to measure background signals).

NOTE: The final concentrations of 4-MU in the reaction volume (50 $\mu \mathrm{L} 4-\mathrm{MU}+50 \mu \mathrm{L} 300 \mu \mathrm{M}$ MUNANA) are $2.5 \mu \mathrm{M}, 5 \mu \mathrm{M}, 10 \mu \mathrm{M}, 20 \mu \mathrm{M}, 40$ $\mu \mathrm{M}, 80 \mu \mathrm{M}, 160 \mu \mathrm{M}$ and $320 \mu \mathrm{M}$.

4. Prepare a $2.5 \mathrm{mM}$ MUNANA stock solution by reconstituting $25 \mathrm{mg}$ of MUNANA in $20 \mathrm{~mL}$ of distilled water. Mix $0.72 \mathrm{~mL}$ of $2.5 \mathrm{mM}$ MUNANA with $5.28 \mathrm{~mL}$ of $1 \mathrm{x}$ assay buffer to obtain a $300 \mu \mathrm{M}$ MUNANA working solution (sufficient volume for one plate). Cover the tube containing the $300 \mu \mathrm{M}$ MUNANA working solution with aluminum foil and keep it on ice unless used immediately. Discard any leftover materials. NOTE: The $2.5 \mathrm{mM}$ MUNANA stock solution can be stored at $-20^{\circ} \mathrm{C}$ for 1 month and must be used within one freeze/thaw cycle. The 4-MU and MUNANA solutions are light sensitive and must be protected from prolonged light exposure.

5. Add $50 \mu \mathrm{L}$ of $300 \mu \mathrm{M}$ MUNANA to each well, gently tap to mix, and incubate at $37^{\circ} \mathrm{C}$ for $30 \mathrm{~min}$. Cover the plate with a plate sealer to prevent evaporation.

NOTE: This step is to account for the background fluorescence in the NA inhibition assay.

6. Prepare the stop solution by mixing $11 \mathrm{~mL}$ of absolute ethanol with $2.225 \mathrm{~mL}$ of $0.824 \mathrm{M} \mathrm{NaOH}$ (sufficient volume for one plate).

7. Add $100 \mu \mathrm{L}$ of stop solution to each well to stop the reaction and gently tap to mix.

8. Read the plate using a fluorometer with an excitation wavelength setting of $355 \mathrm{~nm}$ and an emission wavelength setting of $460 \mathrm{~nm}$, as per the manufacturer's instructions.

9. Calculate the average background signal using fluorescence signals from all the wells containing no 4-MU. Subtract this average background signal from each of the wells containing 4-MU and calculate the average signals (RFU) for each 4-MU concentration. Plot a standard curve of RFU against the 4-MU concentration $(\mu \mathrm{M})$, as shown in Figure 1a; a close-up linear section of the curve is shown in Figure $1 \mathrm{~b}$.

10. Visualize the plot of RFU against 4-MU concentration $(\mu \mathrm{M})$ to determine the linear range and the optimal target signal; the linear range is where the fluorescence signal increases proportionately to the increasing concentrations of the 4-MU on the plot, while the optimal target signal is an arbitrary 4-MU concentration within the linear range.

NOTE: The linear range and the optimal target signal are fluorometer-specific. For example, the fluorometer at the Melbourne WHOCCRRI has a linear range of 2.5-40 $\mu \mathrm{M}$ 4-MU and an optimal target signal of $\sim 30 \mu \mathrm{M} 4-\mathrm{MU}$, which corresponds to $\sim 1,500 \mathrm{RFU}$.

\section{Determining the NA Activity of the Viruses}

NOTE: Influenza viruses are cultured to sufficient titers in Madin-Darby Canine Kidney (MDCK) cells or embryonated chicken eggs ${ }^{8}$.

1. Dispense $120 \mu \mathrm{L}$ per well of undiluted cultured influenza viruses into column 1 and $60 \mu \mathrm{L}$ of $1 \mathrm{x}$ assay buffer containing $0.1 \%$ NP-40 into the remaining 11 columns of a 96 -well, U-bottom plate.

2. Serially perform two-fold dilution of the viruses across the plate (i.e., transfer $60 \mu \mathrm{L}$ from column 1 to column 2 and so forth, up to column 11 ) using a multichannel pipette, leaving column 12 as a blank containing only $1 \mathrm{x}$ assay buffer.

3. Transfer $50 \mu \mathrm{L}$ from each of the wells (diluted viruses and blanks) into a clear, 96-well, flat-bottom plate. NOTE: It is not necessary to change pipette tips if materials are transferred from column 12 through to column 1.

4. Add $50 \mu \mathrm{L}$ of $300 \mu \mathrm{M}$ MUNANA (prepared as per step 1.4) per well and gently tap the plate to mix. Incubate the plate at $37^{\circ} \mathrm{C}$ for $1 \mathrm{~h}$. Cover the plate with a plate sealer to prevent evaporation.

5. Add $100 \mu \mathrm{L}$ of stop solution (prepared as per step 1.6) per well to terminate the reaction and gently tap the plate to mix.

6. Read the plate using a fluorometer.

1. Use an excitation wavelength setting of $355 \mathrm{~nm}$ and an emission wavelength setting of $460 \mathrm{~nm}$.

7. Determine the average background signal based on the fluorescence readings in column 12 and subtract the average background signal from each well. Plot a graph of RFU against virus dilutions. 
NOTE: The background values for $100 \mu \mathrm{M}$ MUNANA at the WHOCCRRI Melbourne are typically between 50 and 120 RFU, but these will differ depending on the fluorometer being used.

8. View the plot of RFU against virus dilutions to determine the mid-point of the linear section of the curve for each virus (Figure 2). Use the optimal target signal (determined in step 1) as the reference point.

NOTE: This should correspond with the 4-MU linear range of the fluorometer determined in section 1 and will provide the appropriate concentration of viruses to be used in section 3 .

\section{Assessing Virus Susceptibility to NA Inhibitors Using the NA Inhibition Assay}

1. Prepare master stocks of NA inhibitors at concentrations of $\mathbf{3 0 0} \mu \mathrm{M}$.

1. Prepare $300 \mu \mathrm{M}$ zanamivir (molecular weight, $\mathrm{MW}=332.32 \mathrm{~g} / \mathrm{mol}$ ) by dissolving $5.0 \mathrm{mg}$ of zanamivir in $50 \mathrm{~mL}$ of $2 \mathrm{x}$ assay buffer (66.6 $\mathrm{mM}$ MES and $8 \mathrm{mM} \mathrm{CaCl}_{2}, \mathrm{pH} 6.5$ ).

2. Prepare $300 \mu \mathrm{M}$ oseltamivir carboxylate (D-tartrate; $\mathrm{MW}=386.44 \mathrm{~g} / \mathrm{mol}$ ) by dissolving $5.8 \mathrm{mg}$ in $50 \mathrm{~mL}$ of $2 x$ assay buffer.

3. Prepare $300 \mu \mathrm{M}$ peramivir trihydrate (MW $=382.45 \mathrm{~g} / \mathrm{mol}$ ) by dissolving $5.7 \mathrm{mg}$ in $50 \mathrm{~mL}$ of $2 \mathrm{x}$ assay buffer.

4. Prepare $300 \mu \mathrm{M}$ laninamivir ( $\mathrm{MW}=346.34 \mathrm{~g} / \mathrm{mol}$ ) by dissolving $5.2 \mathrm{mg}$ in $50 \mathrm{~mL}$ of $2 \mathrm{x}$ assay buffer.

NOTE: The NA inhibitor master stocks can be stored at $-20^{\circ} \mathrm{C}$ for 12 months. Check the MW of the NA inhibitors to ensure the correct weights and volumes are used in reconstitution. The oseltamivir carboxylate is the active compound of the prodrug oseltamivir phosphate. Therefore, only the oseltamivir carboxylate should be used in the NA inhibition assay.

2. From the master stocks, prepare working stocks of ten-fold serial dilutions of the NA inhibitors in $50 \mathrm{~mL}$ centrifuge tubes at concentrations of $0.03 \mathrm{nM}, 0.3 \mathrm{nM}, 3 \mathrm{nM}, 30 \mathrm{nM}, 300 \mathrm{nM}, 3,000 \mathrm{nM}$, and $30,000 \mathrm{nM}$ in $2 x$ assay buffer (66.6 mM MES and $8 \mathrm{mM} \mathrm{CaCl}_{2}, \mathrm{pH} 6.5$ ); this is for use across multiple assays.

NOTE: The final concentrations of NA inhibitors in the reaction volume $(50 \mu \mathrm{L}$ of virus dilution $+50 \mu \mathrm{L}$ of NA inhibitor $+50 \mu \mathrm{L}$ of $300 \mu \mathrm{M}$ MUNANA) are $0.01 \mathrm{nM}, 0.1 \mathrm{nM}, 1 \mathrm{nM}, 10 \mathrm{nM}, 100 \mathrm{nM}, 1,000 \mathrm{nM}$, and 10,000 nM, respectively. The final concentration does not include the $100 \mu \mathrm{L}$ of stop solution. Store all NA inhibitors dilutions at $2-8{ }^{\circ} \mathrm{C}$. The expiry date is the same as that of the master stocks.

3. Prepare the virus dilutions in $1 x$ assay buffer containing $0.1 \%$ NP-40 surfactant in a 96-deep-well block. Use virus dilutions based on the NA activity assay results derived from section 2 . Use a total volume of $2 \mathrm{~mL}$ per virus to test four NA inhibitors.

NOTE: Prepare two wells (1 mL per well) per virus in a 96-deep-well block. Examples of virus dilutions for VIRUS 1, 2, and 3 are shown in Table 1.

4. Dispense the required volume of NA inhibitors (prepared as per step 3.2) into an 8 deep-well reservoir. From there, dispense $50 \mu \mathrm{L}$ of $\mathrm{NA}$ inhibitors at dilutions ranging from $0 \mathrm{nM}$ (2x assay buffer only) to $30,000 \mathrm{nM}$ in rows $\mathrm{A}$ to $\mathrm{H}$ in a clear, 96 -well, flat-bottom plate. NOTE: The plate layout is illustrated in Figure 3.

5. Add $50 \mu \mathrm{L}$ of diluted test viruses per well to columns $1-11$ and $50 \mu \mathrm{L}$ per well of $1 \mathrm{x}$ assay buffer only to column 12 . Gently tap the plate to mix and incubate at room temperature for $45 \mathrm{~min}$. Cover the plate with a plate sealer to prevent evaporation.

6. Add $50 \mu \mathrm{L}$ of $300 \mu \mathrm{M}$ MUNANA (prepared as per step 1.4) per well and gently tap the plate to mix. Incubate the plate at $37^{\circ} \mathrm{C}$ for $1 \mathrm{~h}$. Cover the plate with a plate sealer to prevent evaporation.

7. Add $100 \mu \mathrm{L}$ of stop solution (prepared as per step 1.6) to each well and gently tap the plate to mix.

8. Read the plate using a fluorometer.

1. Use an excitation wavelength of $355 \mathrm{~nm}$ and an emission wavelength of $460 \mathrm{~nm}$, as described previously.

\section{Calculation of $\mathrm{IC}_{50}$ Values}

NOTE: The JASPR v1.2 is curve-fitting software that enables the calculation of $\mathrm{IC}_{50}$ values. The software was developed by the Influenza Division at the CDC, Atlanta, USA. The software utilizes the equation: $V=V_{\max } \times\left(1-\left([] /\left(\mathrm{K}_{\mathrm{i}}+[I]\right)\right)\right)$, where $V_{\max }$ is the maximum rate of metabolism, $[I]$ is the inhibitor concentration, $V$ is the response being inhibited, and $K_{\mathrm{i}}$ is the $\mathrm{IC}_{50}$ for the inhibition curve.

1. Copy and paste the raw data outputted by the fluorometer into a spreadsheet in a 12-column plate format (96-well), starting with cell A1. NOTE: Raw data from each subsequent plate must be staggered by one empty row. If each virus has been tested against four NA inhibitors, paste the raw data in a set of four (with an empty row between each plate).

2. Open the fitting software and click on the "Experiment" tab. Choose "Alternative 2-drug Fluoro 11 Samples."

3. Click on the "Options" tab and tick "Generate Graphs."

4. Click on the "Options" again and click on the "New Key" tab. Save the "inhibition_key" .csv file in the same folder as the raw data spreadsheet file.

5. In the inhibition_key file, list all sample names below the ID. Each sample name must be unique.

6. If four NA inhibitors were tested, insert spaces for two additional rows below Oseltamivir and type in "Peramivir" and "Laninamivir." Save the changes made to the inhibition_key file.

7. Return to the "jaspr v 1.2-Inhibition Curve fitting" window and select the raw data file as the "Experiment File" and inhibition_key as the "Key File." Run the analysis. Save the results in .csv and .pdf formats.

NOTE: The software will automatically plot an inhibition curve (RFU against NA inhibitor concentrations), as shown in Figure 4 . The program also calculates $\mathrm{IC}_{50}$ values for each virus against an individual NA inhibitor (Figure 4). Additionally, JASPR presents the IC $\mathrm{C}_{50}$ values and the signal-to-background (S/B) ratio in spreadsheet format. The background values can differ from lab to lab depending on the fluorometer used. At the Melbourne WHOCCRRI, the background values for $100 \mu \mathrm{M}$ MUNANA range from 50 to 120 RFU. For a reliable IC 50 value, an S/B ratio of $\geq 10$ is preferred, although a ratio of less than 10 is still acceptable, particularly for mutant viruses that have very low NA activity.

8. Inspect the $\mathrm{IC}_{50}$ values and the curve shapes generated by the software. All the data points should fall on or close to the curve; if they do not, repeat the NA inhibition assay.

NOTE: For viruses that show unusually high $\mathrm{IC}_{50}$ values, the assay should be repeated to confirm the result. 


\section{Representative Results}

Using standardized reporting guidelines from the WHO Working Group on Surveillance of Influenza Antiviral Susceptibility ${ }^{9}$, the susceptibility of influenza viruses to the NA inhibitors are reported using the terms normal inhibition ( $\mathrm{NI}$ ), reduced inhibition (RI), and highly reduced inhibition (HRI). $\mathrm{NI}$ viruses are those with $\mathrm{IC}_{50}$ values less than 10 -fold compared to the reference median $\mathrm{IC}_{50}$ for influenza $\mathrm{A}$ viruses (or less than 5 -fold for influenza $B$ viruses). RI viruses are those with $I C_{50}$ values between 10 - and 100 -fold above the reference median $I C_{50}$ for influenza $A$ viruses (or 5- and 50-fold for influenza B). HRI viruses are those with $\mathrm{IC}_{50}$ values of 100 -fold above the reference median $\mathrm{IC}_{50}$ for influenza $\mathrm{A}$ viruses (or above 50 -fold for influenza B viruses); see Table 2.

The reference median $\mathrm{IC}_{50}$ values for $\mathrm{A}(\mathrm{H} 1 \mathrm{~N} 1)$ pdm09, $\mathrm{A}(\mathrm{H} 3 \mathrm{~N} 2)$, and $\mathrm{B}$ Yamagata/B Victoria viruses are calculated and updated annually at the Melbourne WHOCCRRI to reflect minor changes in the $I_{50}$ values of circulating influenza strains to the NA inhibitors (Table 3). The median $\mathrm{IC}_{50}$ values in influenza $\mathrm{A}(\mathrm{H} 1 \mathrm{~N} 1)$ pdm09 viruses are almost the same across the four NA inhibitors, but the median zanamivir and laninamivir $I_{50}$ values for $A(H 3 N 2)$ viruses are 2- to 4-fold higher compared to oseltamivir and peramivir $I_{50}$ values (Table 3 ). The median oseltamivir IC ${ }_{50}$ value for influenza $B$ viruses is generally 5 - to 10 -fold higher than the zanamivir, peramivir, and laninamivir $I_{50}$ values (Table 3 ).

The NA inhibition assay is a phenotypic assay that does not provide information on the genetic changes associated with RI or HRI. Therefore, it is important that genetic analysis is performed following the identification of viruses with RI or HRI. At the Melbourne WHOCCRRI, the NA gene of variants is analyzed using Sanger sequencing and pyro-sequencing. A representative list of amino acid substitutions that can be found in the NA gene of viruses with RI and HRI variants is presented in Table 4. A more extensive list of amino acid substitutions that can alter NAI susceptibility is also available on the WHO website ${ }^{10}$.

a)

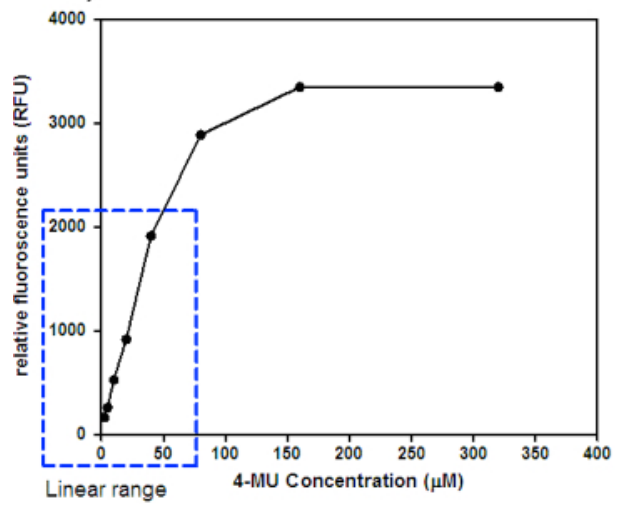

b)

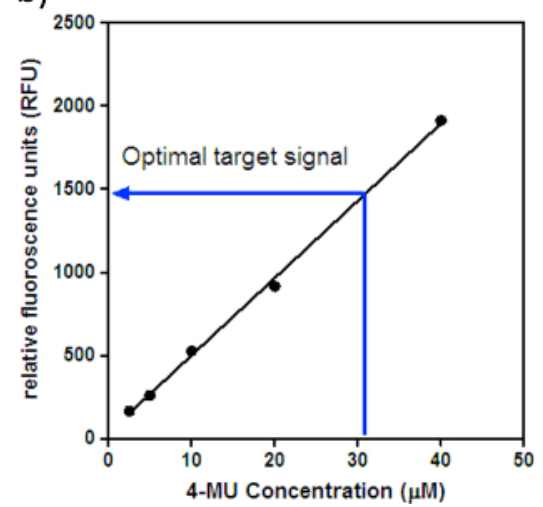

Figure 1: RFU against 4-MU concentration. (a) Standard curve of RFU against 4-MU concentration $(\mu M)$. The dotted box shows the linear range of 4-MU for the fluorometer. The fluorescence signals above the linear range may be saturated, and therefore, any small changes in fluorescence may not be detected by the fluorometer. (b) Close-up linear section of the standard curve of Figure 1a for the identification of the "optimal target signal." The fluorometer at the Melbourne WHOCCRRI has a linear range of 2.5-40 $\mu \mathrm{M}$ 4-MU and an optimal target signal of $\sim 30$ $\mu \mathrm{M}$ 4-MU, which corresponds to $\sim 1,500$ RFU. Please click here to view a larger version of this figure.

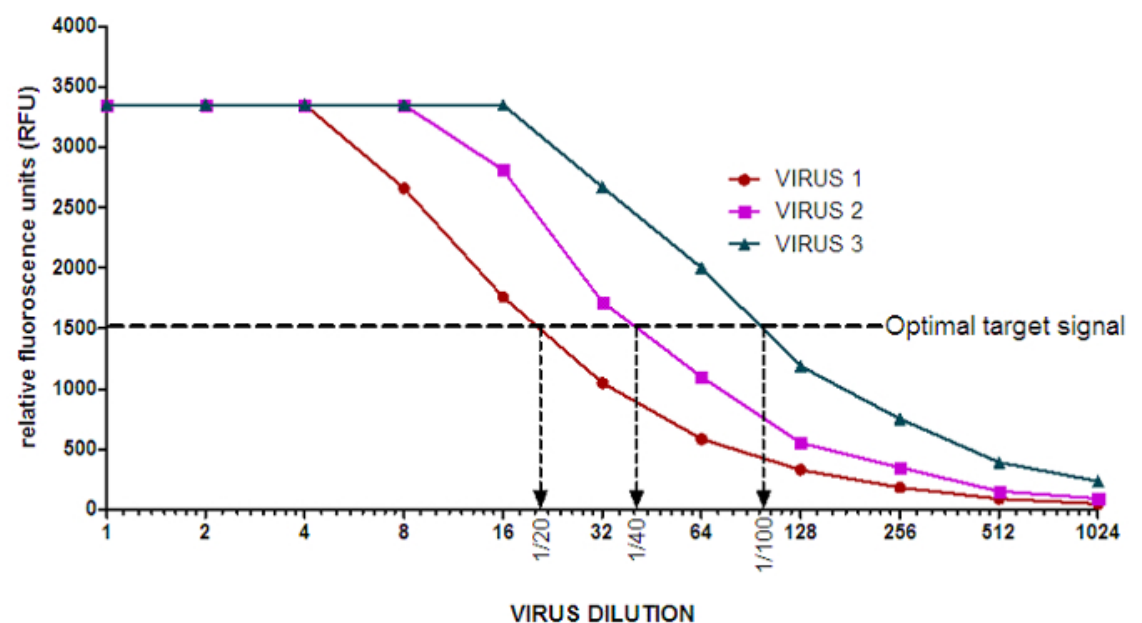

Figure 2: Example of the NA activity curves of influenza viruses. The average background value of 50.61 RFU has been subtracted from every dilution point on the NA activity curves. The arrows indicate the appropriate virus dilution to use in the NA inhibition assay for each virus. For easier preparation of virus dilutions, one may choose to perform a 1/100 dilution for VIRUS 3 instead of a 1/96 dilution. Please click here to view a larger version of this figure. 


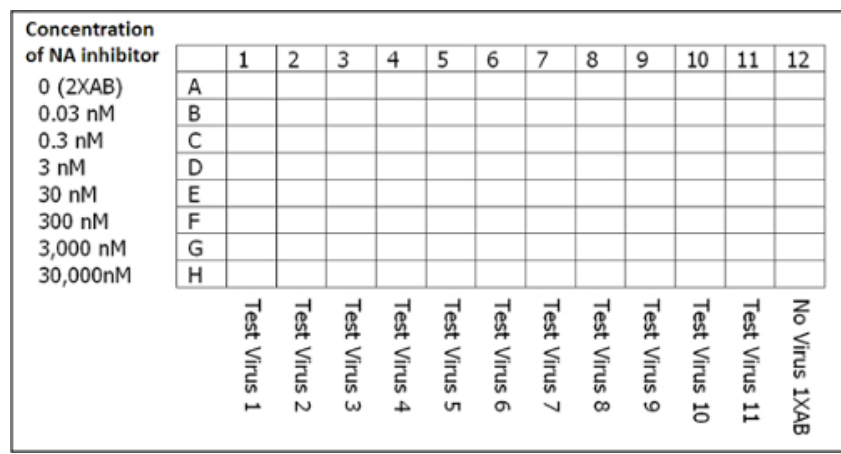

Figure 3: Plate layout for the setup of the NA inhibition assay. Each plate includes the last column, which acts as a negative control that contains no virus but only $1 x$ assay buffer (AB), NA inhibitor, MUNANA, and stop solution. NOTE: JASPR uses readings from column 12 of each plate to determine the average blank signal used in the calculation of the $\mathrm{IC}_{50}$ values. Please click here to view a larger version of this figure.

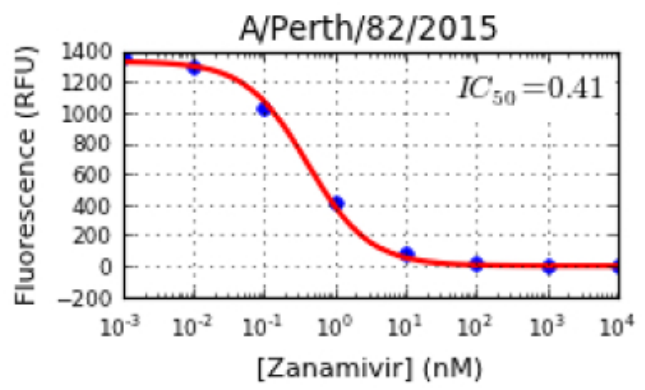

Figure 4: Example of an inhibition curve and $I_{50}$ value of an $A(H 1 N 1) p d m 09$ virus, $A / P e r t h / 82 / 2015$. The JASPR software presents the inhibition curve as fluorescence (RFU) against the increasing concentration (nM) of NA inhibitor, with every point fit within the curve. Based on the inhibition curve, the $\mathrm{IC}_{50}$ value is determined as the concentration of NA inhibitor to reduce $50 \%$ of the virus NA activity. Please click here to view a larger version of this figure.

\begin{tabular}{|l|l|l|l|l|}
\hline Virus & Virus dilution required & 1 x assay buffer volume $(\mu \mathrm{L})$ & $\begin{array}{l}\text { Surfactant-Amps-NP-40 } \\
(10 \%)(\mathrm{mL})\end{array}$ & Virus volume $(\mathrm{mL})$ \\
\hline 1 & $1 / 20$ & 940 & 10 & 50 \\
\hline 2 & $1 / 40$ & 965 & 10 & 25 \\
\hline 3 & $1 / 100$ & 890 & 10 & 10 \\
\hline
\end{tabular}

Table 1: Preparation of virus dilutions for VIRUS 1, 2, and 3 in the NA inhibition assay.

\begin{tabular}{|l|l|l|l|}
\hline \multirow{2}{*}{ Virus type/subtype/lineage } & Normal inhibition & Reduced inhibition & Highly reduced inhibition \\
\cline { 2 - 4 } & $(\mathrm{NI})$ & $(\mathrm{RI})$ & $(\mathrm{HRI})$ \\
\hline $\mathrm{A}(\mathrm{H} 1 \mathrm{~N} 1)$ pdm09 & $<10$ fold & $10-100$ fold & $>100$ fold \\
\hline $\mathrm{A}(\mathrm{H} 3 \mathrm{~N} 2)$ & $<10$ fold & $10-100$ fold & $>100$ fold \\
\hline B Yamagata and B Victoria & $<5$ fold & $5-50$ fold & $>50$ fold \\
\hline
\end{tabular}

Table 2: The WHO Antiviral Working Group recommended guidelines for the classification of influenza virus susceptibility to NA inhibitors.

\begin{tabular}{|l|l|l|l|l|l|}
\hline $\begin{array}{l}\text { Virus type/subtype/ } \\
\text { lineage }\end{array}$ & $\mathrm{N}$ & Zanamivir & Oseltamivir & Peramivir & Laninamivir \\
\cline { 3 - 6 } & & $\begin{array}{l}\text { Median (range) } \mathrm{IC}_{50} \\
\mathrm{nM}\end{array}$ & $\begin{array}{l}\text { Median (range) } \mathrm{IC}_{50} \\
\mathrm{nM}\end{array}$ & $\begin{array}{l}\text { Median }(\text { range }) \\
\mathrm{nM}\end{array}$ & $\begin{array}{l}\text { Median }(\mathrm{range}) \mathrm{IC}_{50} \\
\mathrm{nM}\end{array}$ \\
\hline $\mathrm{A}(\mathrm{H} 1 \mathrm{~N} 1)$ pdm09 & 1,326 & $0.42(0.1-3.43)$ & $0.36(0.01-3.48)$ & $0.19(0.07-1.60)$ & $0.55(0.05-2.29)$ \\
\hline $\mathrm{A}(\mathrm{H} 3 \mathrm{~N} 2)$ & 1,654 & $0.9(0.11-4.0)$ & $0.38(0.01-3.65)$ & $0.33(0.12-3.06)$ & $1.38(0.01-9.38)$ \\
\hline $\begin{array}{l}\mathrm{B} \text { Yamagata and B } \\
\text { Victoria }\end{array}$ & 1,115 & $2.2(1.24-10.72)$ & $15.12(2.39-70.75)$ & $1.36(0.57-6.67)$ & $2.89(1.62-9.15)$ \\
\hline
\end{tabular}

Table 3: Median $\mathrm{IC}_{50}$ and $\mathrm{IC}_{50}$ range of normal inhibition (NI) viruses from 2015 derived in the WHO CCRRI, Melbourne. 


\begin{tabular}{|c|c|c|c|c|c|}
\hline \multirow{2}{*}{$\begin{array}{l}\text { Amino acid } \\
\text { substitution }\end{array}$} & \multirow[t]{2}{*}{ Type/subtype/lineage } & \multicolumn{4}{|c|}{$\mathrm{IC}_{50}$ fold-change compared to reference median $\mathrm{IC}_{50}$ values. } \\
\hline & & Zanamivir & Oseltamivir & Peramivir & Laninamivir \\
\hline $\mathrm{H} 275 \mathrm{Y}$ & $\mathrm{A}(\mathrm{H} 1 \mathrm{~N} 1) \mathrm{pdm09}$ & 1 & $557(\mathrm{HRI})$ & $123(\mathrm{HRI})$ & 2 \\
\hline E119V & $\mathrm{A}(\mathrm{H} 3 \mathrm{~N} 2)$ & 1 & $63(\mathrm{RI})$ & 1 & 1 \\
\hline $\mathrm{H} 134 \mathrm{Y}$ & B Victoria & 1 & 4 & $76(\mathrm{HRI})$ & 2 \\
\hline N151T & B Victoria & 4 & 4 & $42(\mathrm{HRI})$ & 1 \\
\hline G104E & B Victoria & $1,220(\mathrm{HRI})$ & $87(\mathrm{HRI})$ & $17,724(\mathrm{HRI})$ & 701 (HRI) \\
\hline E105K & B Victoria & 3 & $5(\mathrm{RI})$ & 59 (HRI) & 2 \\
\hline I222T & B Victoria & 2 & $7(\mathrm{RI})$ & $8(\mathrm{RI})$ & 3 \\
\hline $\mathrm{H} 273 \mathrm{Y}$ & B Yamagata & 1 & 230 (HRI) & 377 (HRI) & 2 \\
\hline D197N & B Yamagata & 4 & $7(\mathrm{RI})$ & $32(\mathrm{RI})$ & 3 \\
\hline
\end{tabular}

Table 4: Representative list of amino acid substitutions linked to reduced inhibition (RI) or highly reduced inhibition (HRI) to NA inhibitors.

\begin{tabular}{|c|c|c|}
\hline Problem & Possible reason(s) & Solution(s) \\
\hline \multirow[t]{2}{*}{ No or low NA activity } & No virus was present or low virus yield. & $\begin{array}{l}\text { Clinical specimen must be cultured in cell lines } \\
\text { (i.e. Madin-Darby Canine Kidney cells) or in } \\
\text { embryonated chicken eggs to a higher virus } \\
\text { load for use in the NA inhibition assay. }\end{array}$ \\
\hline & $\begin{array}{l}\text { Some mutant viruses have extremely low NA } \\
\text { activity despite at high virus load. }\end{array}$ & $\begin{array}{l}\text { Use neat virus concentration for testing. } \\
\text { Lower } \mathrm{pH} \text { assay buffer (e.g. } \mathrm{pH} \text { 5.3) may be } \\
\text { used. However, caution must be taken when } \\
\text { comparing data. }\end{array}$ \\
\hline \multirow[t]{3}{*}{ No or low NA activity in NA inhibition assay } & No virus was added. & $\begin{array}{l}\text { Re-dilute the virus. Ensure the virus is directly } \\
\text { added into the } 1 x \text { assay buffer. }\end{array}$ \\
\hline & Wrong virus dilution was used. & Repeat the NA activity assay. \\
\hline & Insufficient incubation time. & Ensure the incubation time is followed. \\
\hline \multirow[t]{3}{*}{ Data points fall outside the $\mathrm{IC}_{50}$ curve } & \multirow[t]{2}{*}{$\begin{array}{l}\text { Cross contamination of NA inhibitor of higher } \\
\text { concentration. }\end{array}$} & $\begin{array}{l}\text { Ensure that the tips are not in contact with the } \\
\text { NA inhibitor when dispensing diluted viruses } \\
\text { into the } 96 \text { well plate. }\end{array}$ \\
\hline & & $\begin{array}{l}\text { If an } 8 \text { deep well reservoir was used, discard } \\
\text { and re-dispense the NA inhibitor concentrations } \\
\text { into a fresh } 8 \text { deep well reservoir. }\end{array}$ \\
\hline & $\begin{array}{l}\text { The volume of the NA inhibitor or MUNANA or } \\
\text { diluted virus was not added equally into each } \\
\text { well. }\end{array}$ & $\begin{array}{l}\text { Repeat the assay with a calibrated multi- } \\
\text { channel pipette. Ensure equal volume of each } \\
\text { reagent is dispensed into each well. }\end{array}$ \\
\hline \multirow[t]{3}{*}{ Unusually high $\mathrm{IC}_{50}$ values } & Too high concentration of virus was added. & $\begin{array}{l}\text { Repeat the NA activity assay and NA inhibition } \\
\text { assay. }\end{array}$ \\
\hline & $\begin{array}{l}\text { Test sample contained mixtures of influenza A } \\
\text { and influenza B. }\end{array}$ & $\begin{array}{l}\text { Perform real-time PCR to identify the presence } \\
\text { of virus mixtures. }\end{array}$ \\
\hline & Bacterial contamination in the sample & $\begin{array}{l}\text { Culture virus in the sterile condition with the } \\
\text { presence of antibiotic. }\end{array}$ \\
\hline \multirow[t]{2}{*}{ High background fluorescence signal } & MUNANA substrate may degrade over time. & Use a new batch of MUNANA subtrate. \\
\hline & $\begin{array}{l}\text { Detection of fluorescence from neighboring } \\
\text { wells. }\end{array}$ & Use black 96 -well flat-bottom plates \\
\hline
\end{tabular}

Table 5: Troubleshooting for potential problems in the NA inhibition assay.

\section{Discussion}

The global monitoring of influenza virus susceptibility to NA inhibitors is currently being conducted by a number of laboratories using either fluorescent or chemiluminescent NA inhibition assays ${ }^{11,12}$. The fluorescent assay is more commonly used than the chemiluminescent assay. Although both assays are robust and reproducible, the $\mathrm{IC}_{50}$ values obtained from the fluorescence-based assay are often higher than the chemiluminescence-based assay, making a direct comparison of the data from the two assays difficult ${ }^{13}$. Even with the use of the same protocol, data generated from one laboratory may vary from another. Because of these variations between laboratories, the WHO Working Group on Surveillance of Influenza Antiviral Susceptibility produced a guideline to assist in inter-laboratory comparisons. Rather than comparing 
the absolute $\mathrm{IC}_{50}$ values, this guideline uses a comparison based on the $\mathrm{IC}_{50}$ fold difference to the median $I \mathrm{C}_{50}$ of the $\mathrm{NI}$ influenza viruses tested in each particular laboratory. The ability to compare data from the five collaborating centers has resulted in the annual publication of global influenza antiviral susceptibility data ${ }^{2,3,4}$. The availability of the large amount of influenza susceptibility data in the public domain allows researchers to compare $\mathrm{IC}_{50}$ data from those studies with that generated in their own laboratories.

Other NA inhibition assays that adopt a similar concept are also commercially available. These commercial kits that contain ready-to-use reagents (NA inhibitors not included) are equally reproducible. However, the in-house NA inhibition assay is substantially cheaper than the commercial kits, because the majority of the reagents can be made in-house in larger quantities and the MUNANA substrate, which previously made up the major cost of the assay, can now be purchased from various sources at competitive prices. The cost of testing one influenza isolate per drug is approximately $\$ 1$ (USD). At the Melbourne WHOCCRRI, improvements have been made to the in-house NA inhibition assay after the incorporation of a robotic platform for the liquid handling components of the assay. Apart from the manual preparation of virus dilutions, the majority of the procedures are performed using the liquid-handling robot. Not only does this minimize manual handling, but it also increases the numbers of assays that can be run in a day.

Although the NA inhibition assay is highly robust, there are a number of critical steps that need to be completed with additional care. First, any irregularity in the NA inhibitor concentrations can shift the inhibition curves and the $\mathrm{IC}_{50}$ values; therefore, careful attention should be paid when preparing the NA inhibitor concentrations. Second, accurate pipetting and precise incubation periods are crucial to maintaining consistent results across assays; this can be achieved by using calibrated pipettes and timers. The inclusion of control viruses in every assay also enables the monitoring of assay performance from assay to assay and over long periods of time. Third, because the NA enzyme activity of seasonal influenza viruses is optimal at $\mathrm{pH} 6.5$, the correct $\mathrm{pH}$ of the assay buffer is important. Some reports have found that the use of lower $\mathrm{pH}$ conditions may improves the identification of influenza variants, such as the $\mathrm{A}(\mathrm{H} 7 \mathrm{~N} 9)$ variant containing the R292K mutation ${ }^{14,15}$. However, the modification to the $\mathrm{pH}$ of the assay buffer will shift the $\mathrm{IC}_{50}$ values, and this may complicate the comparison of data within laboratories and between laboratories. Other modifications and troubleshooting that can be performed are listed in Table 5.

The NA inhibitors are the only class of approved antivirals that are currently effective against circulating influenza viruses. Until other antiviral classes become available for clinical use, the antiviral susceptibility surveillance of circulating influenza viruses will be focused on NA inhibitors alone. Because of the simplicity and reproducibility of results, the use of the NA inhibition assay to assess influenza virus susceptibility to NA inhibitors will continue.

\section{Disclosures}

The authors have nothing to disclose.

\section{Acknowledgements}

The Melbourne WHO Collaborating Centre for Reference and Research on Influenza is supported by the Australian Government Department of Health.

\section{References}

1. Moscona, A. Neuraminidase inhibitors for influenza. N.Engl.J.Med. 353 (13), 1363-1373 (2005)

2. Hurt, A. C. et al. Global update on the susceptibility of human influenza viruses to neuraminidase inhibitors, 2014-2015. Antiviral Res. 132 178-185 (2016).

3. Meijer, A. et al. Global update on the susceptibility of human influenza viruses to neuraminidase inhibitors, 2012-2013. Antiviral Res. 110 31-41 (2014).

4. Takashita, E. et al. Global update on the susceptibility of human influenza viruses to neuraminidase inhibitors, 2013-2014. Antiviral Res. 117 27-38 (2015)

5. Lackenby, A. et al. Emergence of resistance to oseltamivir among influenza $\mathrm{A}(\mathrm{H} 1 \mathrm{~N} 1)$ viruses in Europe. Euro Surveill. 13 (5), (2008).

6. Hurt, A. C. et al. Community transmission of oseltamivir-resistant A(H1N1)pdm09 influenza. N Engl J Med. 365 (26), 2541-2542 (2011).

7. Takashita, E. et al. Characterization of a large cluster of influenza $A(H 1 N 1) p d m 09$ viruses cross-resistant to oseltamivir and peramivir during the 2013-2014 influenza season in Japan. Antimicrob Agents Chemother. 59 (5), 2607-2617 (2015).

8. Eisfeld, A. J., Neumann, G., \& Kawaoka, Y. Influenza A virus isolation, culture and identification. Nat Protoc. 9 (11), $2663-2681$ (2014)

9. Meetings of the WHO working group on surveillance of influenza antiviral susceptibility - Geneva, November 2011 and June 2012 . Wkly Epidemiol Rec. 87 (39), 369-374 (2012).

10. WHO. A summary of amino acid substitutions in the influenza neuraminidase associated with resistance or reduced susceptibility to NAls. http://www.who.int/influenza/gisrs_laboratory/antiviral_susceptibility/avwg2014_nai_substitution_table.pdf?ua=1. 21 October (2016).

11. Okomo-Adhiambo, M., Hurt, A. C., \& Gubareva, L. V. The chemiluminescent neuraminidase inhibition assay: a functional method for detection of influenza virus resistance to the neuraminidase inhibitors. Methods Mol Biol. 865 95-113 (2012).

12. Hurt, A. C., Okomo-Adhiambo, M., \& Gubareva, L. V. The fluorescence neuraminidase inhibition assay: a functional method for detection of influenza virus resistance to the neuraminidase inhibitors. Methods Mol Biol. 865 115-125 (2012).

13. isirv Antiviral Group (isirv-AVG). Analysis of $I C_{50}$ data., <https://isirv.org/site/index.php/methodology/analysis-of-ic50-data> (2016).

14. Sleeman, K. et al. R292K substitution and drug susceptibility of influenza A(H7N9) viruses. Emerg Infect Dis. 19 (9), $1521-1524$ (2013).

15. Gubareva, L. V., Robinson, M. J., Bethell, R. C., \& Webster, R. G. Catalytic and framework mutations in the neuraminidase active site of influenza viruses that are resistant to 4-guanidino-Neu5Ac2en. J Virol. 71 (5), 3385-3390 (1997). 